\title{
HACER EXCEPCIÓN, CUANDO SE HABLA LA LENGUA DE UN CONTINENTE OSCURO: (I) EL CORPUS ENFERMO DE LA AUTOR(A) Y SU DEMANDA DE UNA ESCUCHA POR VENIR ${ }^{1}$
}

\author{
Eleonora CRÓQUER PEDRÓN \\ Centro de Investigaciones Críticas y Socioculturales \\ (Universidad Simón Bolívar)
}

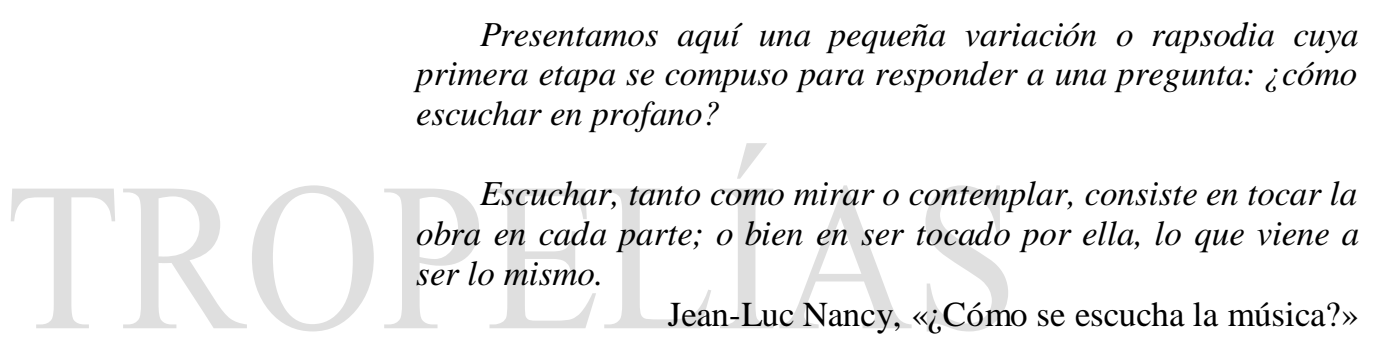

1

$\mathrm{E}$ n el prólogo a ese libro de difícil clasificación, El goce de la histérica (1979), articulado por Lucien Israël a partir de lo que podría pensarse como un reconocimiento casi inconfesable el del médico, respecto de la histérica; o el del saber positivo, si se quiere, a propósito de eso que de ella escapaba a la lógica rectora de su pensamiento, ya de por sí conmocionada y conmovida en Occidente hacia las últimas décadas del siglo XIX-, Sara Glasman propone la siguiente fábula sintetizadora:

\footnotetext{
${ }^{1}$ El presente artículo, primero de una serie de cuatro textos («Hacer excepción, cuando se habla la lengua de un continente oscuro»), que de algún modo se desprenden del desarrollo de la categoría «caso de autor» del cual me he ocupado estos últimos años de investigación y escritura, pasa por mi asistencia al III Congreso Internacional Los textos del cuerpo. El caleidoscopio autorial: textualizaciones del cuerpo-corpus (Barcelona, del 2 al 5 de diciembre de 2014), organizado por el grupo de investigaciones Cuerpo y Textualidad de la Universidad Autónoma de Barcelona, bajo la responsabilidad de Meri Torras. Asimismo, debo su formulación a las proposiciones discutidas con mis estudiantes y colegas del seminario que dicto en la Maestría de Literatura Latinoamericana de la Universidad Simón Bolívar (Venezuela): «De la ficción a la teoría, y viceversa» (enero-marzo de 2015), en torno a la generación de nuevas maneras de confrontarse críticamente con la evidencia que traslucen ciertas «formas profanas» que pulsan por ser escuchadas en/por Ła Cultura. [La «L tachada», «Ł» que acompaña al sustantivo «Cultura» en mayúsculas, es un guiño a la conocida sentencia lacaniana «Ła Mujer no existe» (es decir: ninguna de las mujeres que sí existen la encarnan). Asimismo, dialoga con la «S barrada» con la que Lacan grafica la condición trágica de la noción de «Sujeto» del Humanismo en Occidente: expuesta, por fin, por el psicoanálisis de orientación freudiana, a la demostración de su inconsistencia.
} 


\begin{abstract}
Érase una vez una mujer, que no sabía qué significaba ser mujer para el deseo del hombre, y decidió acudir a preguntarlo a quien presuntamente podía saberlo: un médico. Le llevó su cuerpo sufriente. Dibujó en él una anatomía diferente. Recibió como respuesta la pintura de un cuadro clínico que debía organizar sus síntomas según un ordenamiento de lógica médica. Una estética de la muerte, cuando ella demandaba una ética de vida. Deambuló por diagnósticos, pronósticos, tratamientos, denunciando constantemente la impotencia de un presunto saber. Como era su cuerpo el que gritaba, sólo un médico podría descifrar su pregunta... a condición de escucharla. Y de su encuentro con quien decidió poner en juego su oreja, nació el Psicoanálisis. Elogio, entonces, de la histérica: es fundadora, pero a condición de descubrir luego su trampa. (Israël, 1979: 7)
\end{abstract}

Ficción de origen, según Glasman, para Israël -lector de Freud-, el Psicoanálisis surgiría como la práctica de una escucha distinta. Ésa que demandaba «a gritos» el cuerpo de una mujer atravesada por el Pathos -herida de Pathos-, de cara a cuyo sufrimiento el «Saber» médico, y la escoptofilia que lo paralizara en el punctum de su «observación», presa en/de su propio «deseo» confuso y paradójico, angustiante y embelesado, por otra parte, cual demostrara Didi-Huberman en el trabajo que dedica a la iconografía fotográfica de la Salpêtrière (1982)... Tal «Saber escoptofílico», decía, resultaba impotente, insuficiente, fallido. Como lugar de una insólita coincidencia, desde esta perspectiva, aun cuando haya sido un médico quien decidiera «poner en juego su oreja», fue el grito encarnado de/en una mujer singular lo que llamó significativamente su atención. Una que expresaba la singularidad de su padecimiento, al tiempo que no paraba de indicar, en el exceso de esos sus modos de hacerlo, el topos radicalmente «distinto» del cual procedía su demanda. Una mujer «pa(de)ciente, pues... que, en su padecer, se disponía inusualmente como «sujeto» para un análisis - padeciente, que no sólo paciente; paciente, que ya no posante-... De allí el sentido profundo de lo que este encuentro impensable -este acordado des-encuentro, además; condenado al fracaso, desde el principio- entre dos dis-posiciones asimétricas -amoroso, de algún modo: imposible; pero potente, sin lugar a dudas- supuso para la última modernidad: la (a)puesta en juego de una «oreja» (que no de un «ojo»), allí donde Ello insistía en decirse desde su entraña ${ }^{2}$. En el entre-dos de este (des)encuentro fundacional -y ésta es una de las consideraciones que podrían volver a discutirse hoy- es posible vislumbrar un giro en el Orden del Discurso en Occidente, que dijera Foucault (1970), y en el tipo de relación que éste sostiene con lo Real de sus propios límites, cada vez; con su «afuera» más radical -epistémico y ontológico irrepresentable en/por el lenguaje--

En efecto, lo que el cuerpo descompuesto de esa subjetividad decimonónica -la histérica, moderna por excelencia y sobre-significada en lo social tanto por la literatura y el arte de la época, como por la naciente industria del espectáculo- perseguía resultaba inédito, insólito, en el campo de la ciencia y del pensamiento. Ese cuerpo demandaba una escucha por venir ${ }^{3}$. Aquella que fuera

\footnotetext{
${ }^{2}$ Basta revisar para imaginarlo, no sólo los emblemáticos casos presentados por Freud en torno a la histeria, sino también algunos de sus más tempranos textos, donde todavía es fundamental la referencia a Charcot y a las «histéricas» de la Salpêtrière, que este último reunía y «estudiaba» fotográficamente -la conocida Augustine, recordemos, esa misma «jovencita» arrobada en sus actitudes pasionales, que mereciera el «honor» de ser declarada «Musa del surrealismo», por Louis Aragon y André Breton entre las páginas de La Révolution Surréaliste (1928).

${ }^{3}$ Respecto de esta coincidencia, Padrón (2014) inquiere: «In "Dora", because Freud was perhaps the first to let the hysteric speak her bodily symptoms, finding there a language both constituted by, and seeking the expression in, a thwarted articulated text in its articulation with a secret desire, a text that Freud heard as containing in itself a theory of
} 
capaz de lidiar con la profunda verdad humana -inconsciente, libidinal- que pulsaba más allá de los signos actuados por un cuerpo de mujer, del cual nada podía saberse a ciencia cierta $-\mathrm{y}$ desde un lugar distinto al del confesor o al del Padre, además-. Una escucha situada en la escena de la indagación/elaboración analítica; una vez acordado que lo allí manifiesto pertenece al ámbito de un «no-saber» estructural acerca de la singularidad de lo subjetivo. Esto es: el no ha lugar del «Saber», que tal cuerpo pulsante inscribía por primera vez en Ła Cultura como demanda (de sentido). O, dicho de otra manera: la radical incapacidad de saber acerca de la «diferencia» (Derrida) - el corte- que su establecimiento opera en el «Sujeto»-; y del «goce»-ese «gasto» asociado a lo «femenino», en primera instancia-, que a los gritos (de)muestra la des-compostura orgánica de su existencia -su inefable materialidad de resto-.

Mutatis mutandi... el relato de Glasman me permite introducir ahora la presente serie de desvaríos críticos -«Hacer excepción, cuando se habla la lengua de un continente oscuro»- en torno a tres escrituras de algún modo «distróficas», y fuertemente anudadas a la vida de tres mujeres aún hoy percibidas como «enigmáticas», «raras» y «excéntricas» en el mapa de la historia cultural latinoamericana de la primera mitad del siglo XX. Asimismo, a sus maneras de señalar, entre los textos/cuerpos comunicantes que constituyen su advenimiento al campo de la literatura y el arte, «eso» que hace excepción en Ła Cultura -el goce de/en el Otro-. Es decir: de encarnarlo en la materialidad punzante de una forma convulsa, profanada por lo informe; y textualizarlo, al tiempo, sobre el cuerpo de una mujer -enloquecida, excedida, cicatrizada, de una u otra manera per-formada por la pasión- que con-firma «en carne propia» la «a/e-fectación» del documento entregado «por escrito».

En el marco de una preocupación mayor en cuanto a cierta función cognoscente atribuida a lo «femenino» en Occidente desde los albores de la «civilización», el tipo de «Autor-a» a la que me refiero no «firma» el producto de su trabajo sobre el lenguaje, sino que «con-firma»-firma «con»y certifica: da fe de ello- esa «verdad» donada, como si se tratara de un pedazo de su cuerpo vivo -es una «Autor(a)»-: una Autor-a mujer, exceptuada también por su ser Objeto en/de Ła Cultura. Por otra parte, ella supone un tipo de autoría «anómala»-una suerte de «actoría», podríamos pensar-, que aproxima cierta literatura «dislocada» (fuera de lugar y al margen del tiempo) escrita por mujeres «inasimilables» en América Latina, al ámbito de las artes visuales y escénicas ${ }^{4}$. Pero, más

its own logic and malaise, we can find the seeds of many fundamental psychoanalytic ideas: about fixation and regression, about defenses against unspeakable wishes and desires, about the difficulty in establishing clear criteria of demarcation between the normal and the abnormal, about the inability of human beings to keep secrets if we listen to symptoms as compromise formations between a need to express and a need to repress, about female sexuality ("what did Dora want from me?", asks Freud in "Dora", uncannily doubling in advance his later and famous or infamous question: "what does a woman want?"), about the Oedipus Complex... about transference. These are all themes that appear as the relevant contents in both 'Dora' and Dora. Is there something else?». Y podríamos, además, trazar una línea imaginaria hacia el futuro: desde las discusiones entre Breuer y Freud, a propósito de la conocida «Ana O», y de lo dicho por «ella» en tanto que «Sujeto», hasta la elaboración lacaniana de los cuatro discursos en que su enunciado deviene posición estructura de deseo (Lacan, 1992).

${ }^{4}$ Sobre el problema de la relación entre cuerpo y autoría, y la manera en que ella se manifiesta como neurálgica en/de la modernidad, Meri Torras propone un mapa de consideraciones que permite identificar con claridad hasta qué punto el tipo de autoría al que me refiero en este trabajo realmente funciona de manera «excepcional» (2015). 
aún, esa autoría intrínsecamente «negativa» (crítica), aporética e incómoda, cuya chirriante emergencia entre las voces que se debaten en el terreno del pensamiento y la creación de las primeras décadas del siglo XX en América Latina, trasluce un paradójico inter-és por el no-saber del cual «Ella» dice desde su entraña.

En efecto, el texto $\diamond$ cuerpo incisivo e intenso que esta «auctoría» despliega -texto $\diamond$ cuerpo de Autor(a), que hace excepción a/en la «Razón de Autoridad» con la que se confronta su «habla»funciona ante todo como llamada de atención hacia el continente oscuro que hace a la negatividad constitutiva del «Sujeto», y que en él encuentra una expresión sensible respecto de su propia inmanencia y de los límites de su «Poder». Una expresión que se hace cargo de algunas representaciones anteriores de «mujeres que hablan desde la entraña» en Occidente -el gesto desgarrado de Antígona, por ejemplo, en la tragedia de Sófocles (Cróquer, 1999)-; y anticipa ciertas inquietudes teóricas y retóricas que irán cristalizando a lo largo del tiempo como pensamiento crítico sobre las formas -las que traen a colación algunas propuestas estéticas contemporáneas-; pero también la que interesara al Deleuze de Crítica y Clínica o al Barthes de El placer del texto, actualmente retomadas por autores como Didi-Huberman y Jean-Luc Nancy, entre otros ${ }^{5}$.

Hablo de tres escrituras/escritoras estridentes, hondamente «abismadas» y teatrales, que siguen estando ahí -contenidas, y en gran medida aún hoy amorosamente custodiadas por los cultores y garantes del archivo que certifica su existencia en la Historia-, como demandando una escucha distinta: una escucha capaz de «tocar la obra en cada parte; o bien de ser tocado por ella, lo que viene a ser lo mismo» (Nancy, 2001: 281)... Y hablo de ese texto $\diamond$ cuerpo indisociable en el que lo mostrado, como en un «rapto» de violentas conversiones, es la singular mortificación que el goce precipitado en el significante opera sobre las formas, no sin costo para el sujeto que se hace cargo -ese mismo goce sensible que el semiólogo salvaje, Roland Barthes (entre Lacan y Bataille) pensara como particularmente enfático en algunos textos literarios y artísticos de cara a los cuales proponía una respuesta distinta del lector-:

El escritor de placer (y su lector) acepta la letra; renunciando al goce tiene el derecho y el poder de decirlo: la letra es su placer, está obsesionado por ella, como lo están todos los que aman el lenguaje (no la palabra): los logófilos, escritores, corresponsales, lingüistas; es por lo tanto posible hablar de los textos de placer (aquellos que no ofrecen ningún debate con la anulación del goce): la crítica se ejerce siempre sobre textos de placer, nunca sobre textos de goce: Flaubert, Proust, Stendhal son comentados inagotablemente; la crítica dice entonces el goce vano del texto tutor, el goce pasado o futuro: tienen que leer, yo he leído: la crítica es siempre histórica o prospectiva: el presente constatativo, la presentación del goce le está prohibida, su materia predilecta es la cultura que es todo en nosotros salvo nuestro presente.

Con el escritor de goce (y su lector) comienza el texto insostenible, el texto imposible. Este texto está fuera del placer, fuera de la crítica, salvo que sea alcanzado por otro texto de goce: no se puede hablar

\footnotetext{
${ }^{5}$ A propósito de la potencia crítica de esta emergencia de lo Real del Goce en Ła Cultura, hecho apenas sensible como rumor o como veladura en la literatura y el arte modernos en América Latina -así como llamado a participar como problema en el campo del pensamiento ensayístico y filosófico que lo acompaña- es pertinente revisar la reflexión propuesta por Raúl Antelo, en su ensayo sobre «Jorge Larco e o Conceipto de Cena» (2015). Asimismo, respecto del dislocamiento estructural del sujeto moderno en Occidente, a partir de un desplazamiento de los límites de lo sensible y de lo pensable que acompañan los procesos económicos y sociales de la modernidad avanzada, y los dislocamientos que ella sufre en América Latina, resulta medular el ensayo «Descarga acústica» (2010) de Julio Ramos.
} 
Hacer excepción, cuando se habla la lengua de un continente oscuro

del texto, sólo se puede hablar en él a su manera, entrar en un plagio desenfrenado, afirmar histéricamente el vacío del goce (y no repetir obsersivamente la letra del placer). (1973: 36; énfasis del autor).

En estas escrituras/escritoras... poéticas, según el uso que le da Bataille al término en su ensayo de 1933, «La noción de gasto», sacrificiales, atravesadas por una experiencia de lo «Real», el sentido no se circunscribe tan sólo a lo simbólico. «Lituratierra»-neologismo lacaniano que señala toda una «caída» del semblante a partir del equívoco joyciano que hace devenir «desecho» a una «carta» (Lacan, 1971: 2)-. Letra de Autor(a), ellas se comportan como el territorio erosionado por algo que se «desparrama» allí, en la barra que al mismo tiempo separa y reúne los términos en cuestión. Esto es: como el corpus-cuerpo «enfermo»-de lo vivo que pulsa- de un tipo de escritora baudelaireana, al pie de la letra- que lo sufre en carne propia ${ }^{6}$. Plegadas y desplegadas en el trazo de una mutua profanación -la «letra» deviene «resto»/ la existencia histórica, «caso de excepción»-, una es huella en la otra -y viceversa-. De allí la cosa residual-«joya» y «excremento»- que en ellas parece materializarse. Y de allí, si pensamos en la idea de Giorgio Agamben sobre la «profanación» como aquel acto capaz de «restituir [el Objeto] al libre uso de los hombres» (2005: 95), la enorme potencia crítica que inscriben en Ła Cultura:

El dispositivo que actúa y regula la separación es el sacrificio: a través de una serie de rituales minuciosos, diversos según la variedad de las culturas, que Hubert y Mauss han inventariado pacientemente, sanciona en cada caso el paso de algo profano a lo sagrado, de la esfera humana a la divina. Es esencial la cesura que divide ambas esferas, el umbral que la víctima debe atravesar, no importa si en un sentido u otro. Aquello que ha sido separado ritualmente puede ser restituido por el rito a la esfera profana. Una de las formas más simples de profanación se realiza, así, por contacto (contagione) en el mismo sacrificio que opera y regula el pasaje de la víctima de la esfera humana a la divina. Una parte de aquélla (las vísceras, exta: el hígado, el corazón, la vesícula biliar y los pulmones) queda reservada a los dioses, mientras que el resto puede ser consumido por los hombres. Basta que quienes participan en el rito toquen estas carnes para que se vuelvan profanas y puedan sencillamente ser comidas. Existe un contagio profano, un toque que desencanta y restituye al uso aquello que lo sagrado había separado y petrificado. (Agamben, 2005: 96-97)

$* \quad * \quad *$

La amortajada (1938), de la excesiva chilena María Luisa Bombal (1910-1980), breve novela «imposible», como la definiera Jorge Luis Borges en 1939, acerca de una mujer que, ya muerta y aún insepulta, va recomponiendo su historia de vida -fragmentaria elaboración del desencanto amoroso:

\footnotetext{
${ }^{6}$ «El término poesía», afirma Bataille, «que se aplica a las formas menos degradadas de la expresión de un estado de pérdida, puede ser considerado como sinónimo de gasto. Significa, en efecto, de la forma más precisa, creación por medio de la pérdida. Su sentido es equivalente a sacrificio» (1967: 30); y continúa: «Es cierto que el nombre de poesía no puede ser aplicado, de forma apropiada, más que a una parte bastante poco conocida de lo que viene a designar vulgarmente y que, por falta de una decantación previa, pueden producirse las peores confusiones. Sin embargo, en una primera exposición rápida, es imposible referirse a los límites infinitamente variables que existen entre determinadas formaciones subsidiarias y el elemento residual de la poesía. Es más fácil decir que, para los pocos seres humanos que están enriquecidos por este elemento, el gasto poético deja de ser simbólico en sus consecuencias. Por tanto, en cierta medida, la función creativa compromete la vida misma del que la asume, puesto que lo expone a las actividades más decepcionantes, a la miseria, a la desesperanza, a la persecución de sombras fantasmales, que sólo pueden dar vértigo, o a la rabia».
} 
pathos-grafía... Y la cicatriz en el cuello de María Luisa Bombal, mujer «imposible» y afamada escritora de la vanguardia latinoamericana, con la obra corta de apenas dos relatos (La última niebla y La amortajada), que es huella (evidencia) de su primer y cinematográfico paso al acto fallido de un suicidio. Y el expediente psiquiátrico-policial que registra (deja constancia de) su también frustrado intento de asesinar al amante que la había abandonado diez años antes.

El Diario (1995), de la mexicana Frida Kahlo (1907-1954), reunión irregular de apuntes, poemas, cartas no enviadas, enumeraciones de palabras, dibujos, referencias clínicas y sueños personales borroneados por quien fuera la emblemática pintora de la mexicanidad dignificada, la de los desgarramientos extremos, entre 1944 y 1954... Y el cuerpo de Frida Kahlo: destrozado, intervenido quirúrgicamente, encorsetado, amputado. Y su identidad escindida. Y su sexualidad desbordada, hambrienta y tan maniaca como el rostro proliferado y proliferante que la representa por doquier y a lo largo del tiempo.

A Paixão segundo G.H. (1964), extraño monólogo delirante de la extraña brasileña Clarice Lispector (1920-1977), a través del cual una mujer cualquiera intenta precariamente reanudarse como persona después de una profunda conmoción subjetiva, estado de crisis, experiencia sinestésica de un desencadenamiento significante... Y el rostro-nombre extranjero y espectral de Clarice Lispector. Y su habla enrarecida por el defecto de dicción que le hacía arrastrar las «r». Y la mano quemada por descuido en un accidente doméstico; y los episodios esquizos, y el cáncer de un cuerpo que se secaba, después de todo, de adentro hacia afuera.

Un paso más en esta dirección, quisiera detenerme en un segundo prólogo: el que dedica Gilles Deleuze al conjunto de ensayos que componen su libro fundamental Crítica y clínica (1993). En éste, acerca de su propuesta de una «crítica» dirigida a reconocer la potencia «sanadora» de algunos textos literarios y artísticos de entre los siglos XIX y XX, que registran su delirio al margen de la cosa mortífera y estéril del «estado clínico» -formas profanas (Agamben) en/de la historia cultural de Occidente; pero también Pathosformel (Aby Warburg), portadoras de una enorme carga fantasmática, toda vez que traslucen el evidente anudamiento del deseo y la pulsión en Ła Cultura-, el filósofo explica:

Este conjunto de textos, entre los cuales unos son inéditos y otros ya han sido publicados, se organiza alrededor de unos problemas determinados. El problema de escribir: el escritor, como dice Proust, inventa dentro de una lengua una lengua nueva, una lengua extranjera en cierta medida. Extrae nuevas estructuras gramaticales o sintácticas. Saca a la lengua de los caminos trillados, la hace delirar. Pero asimismo el problema de escribir tampoco es separable de un problema de ver y de oír: en efecto, cuando dentro de la lengua se crea otra lengua, el lenguaje en su totalidad tiende hacia un límite «asintáctico», «agramatical», o que comunica con su propio exterior.

El límite no está fuera del lenguaje, sino que es su afuera: se compone de visiones y de audiciones no lingüísticas, pero que sólo el lenguaje hace posibles. También existe una pintura y una música propias de la escritura, como existen efectos de colores y de sonoridades que se elevan por encima de las palabras. Vemos y oímos a través de las palabras. Beckett hablaba de «horadar agujeros» en el lenguaje para ver u oír «lo que se oculta detrás». De todos los escritores hay que decir: es un vidente, es un oyente, «mal visto mal dicho», es un colorista, un músico. 
Hacer excepción, cuando se habla la lengua de un continente oscuro

Estas visiones, estas audiciones no son un asunto privado, sino que forman los personajes de una Historia y de una geografía que se va reinventando sin cesar. El delirio las inventa como procesos que arrastran las palabras de un extremo a otro del universo. Se trata de acontecimientos en los lindes del lenguaje. Pero cuando el delirio se torna estado clínico, las palabras ya no desembocan en nada, ya no se oye ni se ve nada a través de ellas, salvo una noche que ha perdido su historia, sus colores y sus cantos. La literatura es una salud. (Deleuze, 1993: 9 y 10; las cursivas corresponden al autor, el subrayado me pertenece)

«De lo que ha visto y oído, el escritor regresa con los ojos llorosos y los tímpanos perforados», apunta más adelante en su exposición. Y afirma: «La salud como literatura, como escritura, consiste en inventar un pueblo que falta. Es propio de la función fabuladora inventar un pueblo. No escribimos con los recuerdos propios, salvo que pretendamos convertirlos en el origen o el destino colectivos de un pueblo venidero todavía sepultado bajo sus traiciones y renuncias» (Deleuze, 1993: 14 y 15; énfasis mío).

Dos aspectos me resultan significativos en esta «apuesta» deleuziana por la cualidad «fabuladora» de cierta literatura capaz de hacer estallar un «delirio» al interior de la lengua, que es a la vez intrínseca potencia crítica de las formas en torno a la cual algunos autores y artistas de la modernidad han cifrado la extrema lucidez de sus expresiones. Por una parte, lo que refiere a la elaboración verbal -a la escritura, en tanto desbordamiento (pulsional, deseante) de lo literarioinstitucionalizado; por otra, lo que respecta a la intrínseca relación con el cuerpo que la escritura supone-escribir, para Deleuze, es también ver y oír, y perderse en la experiencia de una visión que sucede más allá de lo visible y/o de una escucha más allá de lo audible, de lo cual «el escritor regresa con los ojos llorosos y los tímpanos perforados»-.

Así gestada en el trazo que inscribe la «loca verdad» de lo humano en Ła Cultura, la escritura es por ello el lugar desde donde, según Deleuze, puede emerger al mundo de lo sensible una significación sepultada. Y una comunidad, en consecuencia: un pueblo siempre por venir. O sea: una «significancia»-para usar un viejo término empleado por Julia Kristeva, entre otros teóricos del grupo de Tel Quel, para referirse a la «productividad llamada texto» (1969)- y un pueblo -y/o un cuerpo- que faltan, allí donde la evidencia de su retorno no puede otra cosa que hacerse sentir como encandilamiento o como resonancia. Esa escritura, sin duda, supone una relación estrecha -y en gran medida tan confusa como fascinante a los ojos y oídos de un lector que deviene escucha de un sentido incomprensible- con la vida arriesgada en el acto de escribir. Asimismo, una «postura autorial» (Meizoz, 2009: 85 y ss.) y un «Ethos» del discurso (Maingueneau, 2009: 49 y ss.) próximos a los que algunos artistas -heroicos y desgarrados: trágicos y teatrales: modernos de signo negativoreclamaran para sí en el tránsito del siglo XIX al XX. Postura y Ethos encarnados de/en aquellos pocos «singulares»-«auctores», como decía en el apartado anterior, «decadentes» y/o «terribles», «raros»- capaces de entregarle su cuerpo al arte y de hacer arte de/con ese cuerpo, en igual medida y con la misma intensidad -como una mujer «histérica», pues, que demanda ser escuchada a través de la verdad de sus excesos-.

En este orden de ideas, las escrituras/escritoras con las cuales propongo confrontarme en este trabajo no responden al corpus-cuerpo que interesa a Deleuze. Y no forman parte, porque son 
escrituras/escritoras en/de la dislocada, incompleta, faltante modernidad latinoamericana, ciertamente; aunque hubieran podido, dada la experiencia de «pérdida» connatural a las múltiples «minoridades» que encarnan en sus distintas corporizaciones/textualizaciones de El goce de la histérica (1979) - de vuelta al principio: ese libro de difícil clasificación donde Lucien Israël rememora los orígenes del psicoanálisis para sostener su propio discurso en defensa de lo que la histérica tiene que decirle/donarle a Ła Cultura-. De hecho, ellas traslucen las dos dimensiones del problema que ocupan al crítico francés en su fragmentaria compilación de textos preliminares. Por una parte, decía en párrafos anteriores, la potencialidad crítica de las formas literarias y artísticas profanadas por «lo vivo que pulsa». Es decir: su capacidad de «hacer sensible» a los ojos y oídos de Ła Cultura aquello -Real- que, por definición, (le) falta -de actuar, pues, en nombre de una «verdad» de otra naturaleza-. Por otra, el carácter singular de esa zona de productividad significante que se abre a la mutua contaminación entre la escritura y la vida desde el cual se dice a sí misma, una hendija mediante la cual algunos textos $\diamond$ cuerpos de la historia cultural de Occidente, profanados de manera significativa por el pathos, recuperan en algo lo profundamente «humano» de ese cuerpo que despunta tanto en la escritura como en la vida -ese cuerpo, su entraña, anticipado o precipitado en las formas-.

Dos cuerpos habitan la subjetividad de Ana María, ya muerta y amortajada en la novela homónima de María Luisa Bombal. Uno yace, literalmente, en la espera de su sepultura; el otro pulsa, deseante y desgarrado en esa fragmentariedad de una reminiscencia insistente del objeto amoroso, que el relato va intensificando como serie de repeticiones - cada nuevo episodio habla de la misma e insoportable imposibilidad del amor, de su inadecuación, su desproporción estructural-. Y todo ello, hasta el momento de una última y orgiástica descomposición física e imaginaria de la mujer que habla en el texto: un desparramamiento del significante -y de la «letra» que deviene «desecho»- allí donde el sujeto «cae» hacia las entrañas -radicalmente inmanentes, terrenales- de lo vivo:

Y he aquí que ella se encuentra sumida en profunda oscuridad.

Y he aquí que se siente precipitada hacia abajo, precipitada vertiginosamente durante un tiempo ilimitado hacia abajo; como si hubieran cavado el fondo de la cripta y pretendieran sepultarla en las entrañas mismas de la tierra.

Y alguien, algo atrajo a la amortajada hacia el suelo otoñal. Y así fue como empezó a descender, fango abajo, por entre las raíces encrespadas de los árboles. Por entre las madrigueras donde pequeños y tímidos animales respiran acurrucados. Cayendo, a ratos, en blandos pozos de helada baba del diablo.

Descendía lenta, lenta, esquivando flores de hueso y extraños seres, de cuerpo viscoso, que miraban por dos estrechas hendiduras tocadas de rocío. Topando esqueletos humanos, maravillosamente blancos e intactos, cuyas rodillas se encogían, como otrora en el vientre de la madre. milenarias.

Hizo pie en el lecho de un antiguo mar y reposó allí largamente, entre pepitas de oro y caracolas

Vertientes subterráneas la arrastraron luego en su carrera bajo inmensas bóvedas de bosques petrificados.

Ciertas emanaciones la atraían a un determinado centro, otras la rechazaban con violencia hacia las zonas de clima propicio a su materia.

¡Ah, si los hombres supieran lo que se encuentra bajo ellos, no hallarían tan simple beber el agua de las fuentes! Porque todo duerme en la tierra y todo despierta de la tierra.

Una vez más la amortajada refluyó a la superficie de la vida. 
Hacer excepción, cuando se habla la lengua de un continente oscuro

En la oscuridad de la cripta, tuvo la impresión de que podía al fin moverse. Y hubiera podido, en efecto, empujar la tapa del ataúd, levantarse y volver derecha y fría, por los caminos, hasta el umbral de su casa.

Pero, nacidas de su cuerpo, sentía una infinidad de raíces hundirse y esparcirse en la tierra como un pujante telaraña por la que subía temblando, hasta ella, la constante palpitación del universo.

$\mathrm{Y}$ ya no deseaba sino quedarse crucificada a la tierra, sufriendo y gozando en su carne el ir y venir de lejanas, muy lejanas mareas; sintiendo crecer la hierba, emerger islas nuevas y abrirse, en otro continente, la flor ignorada que no vive sino en un día de eclipse. Y sintiendo aún bullir y estallar soles, y derrumbarse, quien sabe adónde, montañas gigantes de arena.

Lo juro. No tentó a la amortajada el menor deseo de incorporarse. Sola, podría, al fin, descansar, morir.

Había sufrido la muerte de los vivos. Ahora anhelaba la inmersión total, la segunda muerte: la muerte de los muertos. (Bombal, 1938: 89)

Aún... Ello pulsa en uno de los actos que singularizan -y exceptúan- la presencia de la autora -y de la brevísima escritura que la acompaña- en la escena de la vanguardia latinoamericana. Excéntrica y bien formada intelectual de su época, amiga de Borges y de Neruda, en 1941, diez años después de transcurrido el desencanto amoroso de su relación -asimismo breve- con el aviador Eulogio Sánchez Errázuriz, compró un arma con la que atentó contra el hombre que, entonces, la abandonara. Unos años antes, en el estado depresivo que le desencadenara aquel infeliz affaire, había ya intentado suicidarse con un arma de fuego - lo que inscribiría en su cuello la cicatriz que, entre otros rasgos, ha contribuido a la caracterización de su persona pública a lo largo del tiempo-. Y aún: suicida y presa, protegida por sus amigos y colegas, y redimida luego por la víctima de su desafuero, María Luisa actúa en carne propia una de las improntas más significativas que relata el personaje femenino de la novela escrita por ella en 1938. Un «acting»:

¡Oh, la tortura del primer amor, de la primera desilusión! ¡Cuando se lucha con el pasado, en lugar de olvidarlo! Así persistía yo antes en tender mi pecho blando, a los mismos recuerdos, a las mismas iras, a los mismos duelos.

Recuerdo el enorme revólver que hurté y que guardaba oculto en mi armario, con la boca del caño hundida en un diminuto zapato de raso. Una tarde de invierno gané el bosque. La hojarasca se apretaba al suelo, podrida. El follaje colgaba mojado y muerto, como de trapo.

Muy lejos de la casas me detuve, al fin; saqué el arma de la manga de mi abrigo, la palpé, recelosa, como a una pequeña bestia aturdida que puede retorcerse y morder.

Con infinitas precauciones me la apoyé contra la sien, contra el corazón.

Luego, bruscamente, disparé contra un árbol.

Fue un chasquido, un insignificante chasquido como el que descarga una sábana azotada por el viento. Pero, oh Ricardo, allá en el tronco del árbol quedó un horrendo boquete desparejo y negro de pólvora.

Mi pecho desgarrado así; mi carne, mis venas dispersas... ¡Ay, no, nunca tendría ese valor!

Extenuada me tendí largo a largo, gemí, golpeé el suelo con los puños cerrados. ¡Ay, no, nunca tendría ese valor!

Y sin embargo quería morir, quería morir, te lo juro. (Bombal, 1938: 19)

Lo desbordado que pulsa entre el texto y la vida de la autor(a) latinoamericana -esa histérica exceptuada por/en Ła Cultura que se rebela y se revela, contra los límites de su mandato, y como toda dispuesta en nombre de una escucha por venir-constituye el signo/síntoma de una profanación evidente en las formas de una «cosa-causa» que los vierte el uno en la otra $-\mathrm{y}$ viceversa-, si pensamos en el Diario de Frida Kahlo. Entre los heterogéneos dibujos y palabras arrancados a la deformidad inaudible del «goce»-al silencio de imagen auto-emblematizada del sufrimiento 
individual y colectivo que entregan sus cuadros, con el cual se gana un espacio de visibilidad en la escena de la vanguardia mexicana de las primeras décadas del siglo $\mathrm{XX}$-, esos dibujos y palabras sucedidos, superpuestos, transparentados, borroneados, escamoteados, subrayados, enfatizados... a impulsos, se abren a la posibilidad de una escucha distinta.

Correspondiente a «julio 1953/Cuernavaca», una de las pocas ocurrencias cotidianas datadas en la atípica composición de este «cuaderno de registro»o «libro de autor» presentado a sus lectores como El Diario de Frida Kahlo. Un íntimo autorretrato en 1995 por la colección Debate, con el trazo apresurado de la letra y el énfasis de la entonación que literalmente la sub-raya, también leemos lo que de alguna manera confunde el conocido acertijo oracular de la clásica Esfinge de Tebas con la moderna declaración deseante de una histérica-de-palabra:

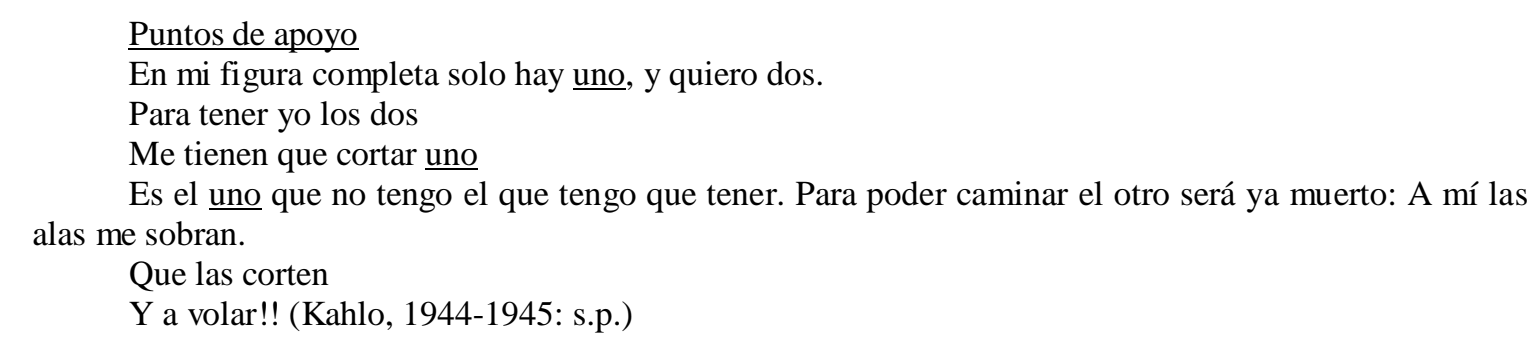

Un dibujo antecede a la escritura: apunte texto-visual respecto de la mirada delirante de una suerte de heterónomo guerrero - una suerte de huno caricaturizado y feminizado en el disfraz-. Al pie de esta imagen la ironía inscribe la punzante literalidad del lema en la disposición significante del montaje: «Tocado nó loco». Más allá del semblante estrafalario que lo «viste», la mirada enajenada del guerrero trasluce el horror de una «caída» anticipada en el pozo profundo en el que se desvanece quien ha perdido -total y definitivamente- la razón. Y semejante pérdida se «dice» con todas las letras que sellan su nombre: un loco es un loco. Pero, más allá de la lectura, un «Uno» que dice sobra en la imagen y el «uno que representa» falta en el texto. Y «eso allí» se señala, con la misma inquietud que entre-tiene a la artista en el arte de sostener sus retazos, mientras se bate a duelo con la muerte escrita por anticipado en las huellas del accidente que atravesara su cuerpo a los 19 años de edad y la impulsara a llenar/significar sin descanso la lamentable catástrofe subjetiva que escribió su destino, en/con sus proliferantes «autorretratos íntimos».

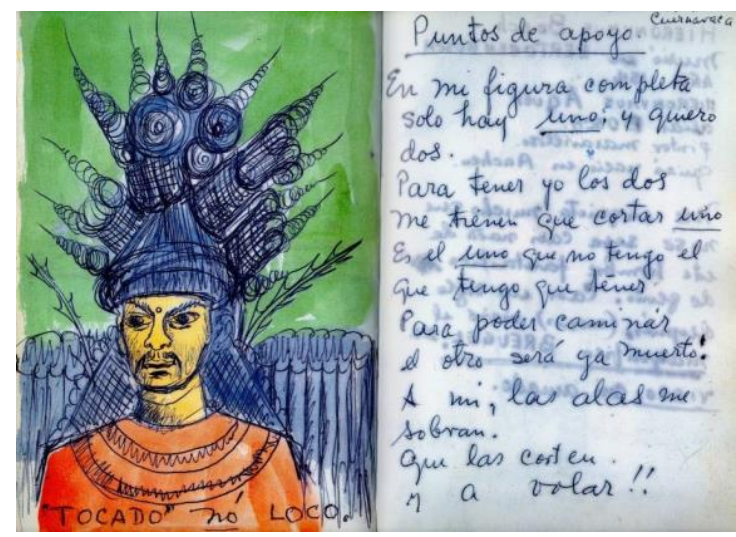


Finalmente, lo fantasmático respira en A Paixão segundo G.H., excepcional novela sobre la angustia delen (el) ser de la hermética brasileña Clarice Lispector, a través de las temporalidades superpuestas entre, por una parte, la elaboración significante vertida por el personaje femenino G.H. hacia/en cierto «Otro» exteriorizado como «mano que escucha, recibe y acompaña» la articulación de un relato (im)posible acerca de lo vivido -el tiempo titubeante de la anamnesis-; y, por otra, la irrupción violenta del delirio - ese estado de presente sin historia ni futuro que hace a la «visión» auto-hipnótica de la protagonista-, desencadenado de nuevo en el marco de aquella su disposición a otorgarle un «sentido» a lo sacrificialmente experimentado en carne viva por ella durante las horas intensas de la mañana anterior -labor «sanadora» de una escritura, que C.L. (en tanto ethos del discurso dedicado «A possíveis leitores») pone en la boca (y entre las manos) de la escultora pa(de)ciente que habla en el texto- .

La nota que sirve de «faro» a tan tortuosa travesía a través del fantasma prefigura los términos singulares en que debe producirse su escucha:

A POSSÍVEIS LEITORES// Este livro é como um livro qualquer. Mas eu ficaria contente se fosse lido apenas por pessoas de alma já formada. Aquelas que sabem que a aproximação, do quer que seja, se faz gradualmente e penosamente -atravessando inclusive o oposto daquilo que se vai aproximar. Aquelas pessoas que, só elas, entenderão bem devagar que este livro nada tira de ninguém. A mim, por exemplo, o personagem G.H. foi dando pouco a pouco uma alegria difícil; mas chama-se alegria.// C.L.

Y las primeras páginas de la novela, a continuación, establecen los términos de su advenimiento:

...estou procurando, estou procurando. Estou tentando entender. Tentando dar a alguém o que vivi e não sei a quem, mas não quero ficar com o que vivi. Não sei o que fazer do que vivi, tenho medo dessa desorganização profunda. No confio no que me aconteceu. Aconteceu-me alguma coisa que eu, pelo fato de não saber como viver, vivi uma outra? A isso quereria chamar desorganização, e teria a segurança de me aventurar, porque saberia depois para onde voltar: para a organização anterior. A isso prefiro chamar desorganização pois não quero me confirmar no que vivi -na confirmação de mim eu perderia o mundo como eu o tinha, e sei que não tenho capacidade para outro. [...]

Ontem no entanto perdi durante horas e horas a minha montagem humana $[\ldots]$

Mai é que também não sei que forma dar ao que me aconteceu. E sem dar uma forma, nada me existe. E -e se a realidade é mesmo que nada existiu?! Quem sabe nada me aconteceu? Só posso compreender o que me acontece mas só acontece o que eu compreendo -que sei do resto? O resto não existiu! Quem sabe me aconteceu apenas uma lenta e grande dissolução? E minha luta contra essa desintegração está sendo esta: a de tentar agora dar-lhe uma forma? Uma forma contorna o caos, uma forma dé construção à substância amorfa - a visão de uma carne infinita é a visão dos loucos, mas se eu cortar a carne em pedaços e distribuí-los pelos dias e pelas fomes - então ela não será mais a perdição e a loucura: será de novo a vida humanizada. [...]

Já que tenho de salvar o dia de amanhã, já que tenho que ter uma forma porque não sinto força de ficar desorganizada, já que fatalmente precisarei enquadrar a monstruosa carne infinita e cortá-la em pedaços assimiláveis pelo tamanho de minha boca e pelo tamanho da visão de meus olhos, já que fatalmente sucumbirei à necessidade de forma que vem de meu pavor de ficar indelimitada -então que pelo menos eu tenha a coragem de deixar que essa forma se forme sozinha como uma crosta que por si mesma endurece, a nebulosa de fogo que se esfria em terra. E que eu tenha a grande coragem de resistir à tentação de inventar uma forma.

Esse esforço que farei agora por deixar subir à tona um sentido, qualquer que seja, esse esforço seria facilitado se eu fingisse escrever para alguém. (Lispector, 1964: 9-11) 
Mientras tanto, el rostro extranjero de la narradora brasileña nacida en Ucrania, y la potencia «reveladora» que se le supone a su habla (Cróquer, 1999), se confunden en la «extrañeza» que la «aparición» de tal texto $\diamond$ cuerpo encarnado en la escritora -Autor(a)-Clarice Lispector desencadena en Ła Cultura. Escucha des-concertada que, por mencionar una anécdota no poco extendida entre biógrafos y críticos, le merece una invitación a participar en el Congreso Mundial de Brujería llevado a cabo en Bogotá, en 1976, adonde acude con ese «exceso» de (su) palabra que es el hermético monólogo delirante «O ovo e a galinha».

Años después de aquel momento de incertidumbres generado por la singular emergencia de Clarice Lispector en la escena literaria brasileña y latinoamericana de su época -y/o años después de que Lispector efectivamente acudiera con un trozo de su escritura a un encuentro de brujería al cual había sido «descabelladamente» invitada-, Emir Rodríguez Monegal inscribe la anécdota en una rara semblanza -una semblanza que es más transcripción de análisis, que agenciamiento de legitimación intelectual-: «Clarice Lispector en sus libros y en mi recuerdo» (1984). El intelectual-sujeto de su discurso hurga en la memoria del profundo interés que haber tenido noticias de aquella «existencia extraña» Clarice Lispector produjo como «huella» en su propia historia de vida -un «misterioso» inter-és en lo humano, que no «mistérico»-; «eso» que punza y pulsa por ser escuchado allí donde «coinciden» una escritura y un cuerpo:

No recuerdo exactamente cuando vi por primera vez el extraño nombre, tan poco brasileño, pero sé que era a principios de los años sesenta, cuando los filmes de James Bond habían popularizado la sigla «Specter» que identificaba una organización terrorista contra la que lucha el superespía británico. Pero sé que la asonancia Lispector/Specter debe haber quedado grabada en alguna área de mi memoria donde pronto se asoció a la imagen visual: una mujer hermosa, de ojos rasgados e insondables, pómulos altos y eslavos, y una boca como una dolorosa herida sensual. La foto y el nombre me anduvieron rondando por un tiempo, bastante antes de que cayera en mis manos su entonces más reciente novela: A maçã no escuro (1961). La leí con interés y un poco de fastidio porque la prosa lenta, exigente, espesa, me obligaba a compartir una angustia existencial que me era ajena: el protagonista padecía la culpa de un crimen que no había cometido, y el lector tenía que cargar esa cruz también. Pero si el tema me abrumaba por sus connotaciones de una religiosidad viscosa, la escritura me hechizaba. Con pocos recursos, usando y abusando de la monotonía y de la obsesión de una narrativa esclava, Clarice Lispector

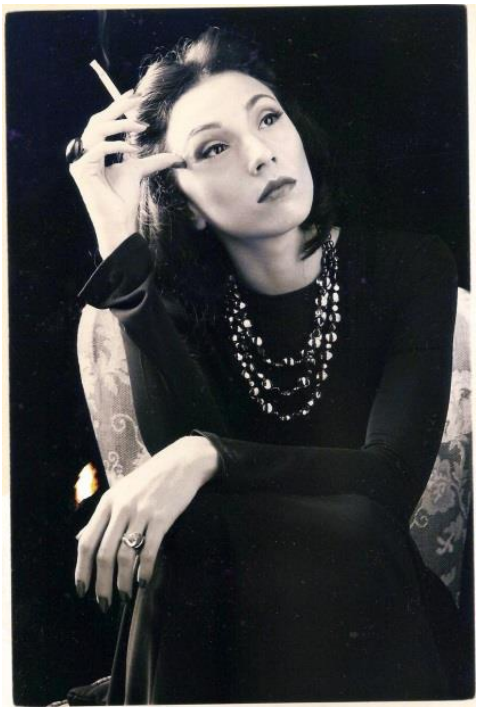
conseguía dominar completamente al lector. Emergí de esa lectura, como de una enfermedad, una fiebre lenta y calma. Busqué más cosas de esa mujer extraña.

Mis siguientes lecturas fueron más fáciles: una novela, A Paixão segundo G. H. (1964), y un cuento, «O ovo e a galinha», que leí en una revista. La novela volvía a aquel mundo de la anterior, pero en una forma más nítida y concentrada. El estilo era el mismo, pero parecía haberse hecho más transparente. La culpabilidad, en este caso, era más general y no dependía de un acto, sino de la condición humana. La protagonista sentía la náusea de vivir, el suspenso sobre la nada, y agonizaba como Jesús, pero lo hacía a partir de una experiencia ridícula por su trivialidad: visitar el cuarto de la sirvienta, descubrir allí otro mundo, enfrentarse con una cucaracha, aplastarla. De esas nadas se pasaba a una experiencia límite: al comer la cucaracha, G. H. salía de lo cotidiano y entraba en la fábula de Kafka. El cuento también acudía a una situación trivial: el dilema sobre la prioridad del huevo o la gallina, pero la escritura de Clarice lo convertía en densa meditación poética. Mi admiración por esta narradora, que se me revelaba así, en tres textos, no conoció límites. Por esa fecha había prometido escribir una panorámica de la novela brasileña de este siglo para la revista Daedalus, de Boston, y escogí a Clarice Lispector, junto con João Guimaraes 


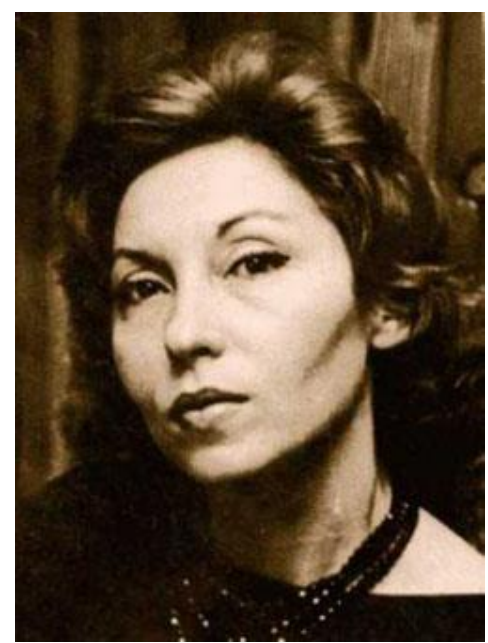

Rosa, como los más altos exponentes de la ficci6n brasileña del medio siglo. Más tarde traduje el articulo para Mundo Nuevo, que entonces dirigía en París (1966), y lo publiqué como introducción a una antología de relatos brasileños, que incluía, naturalmente, «O ovo e a galinha".

Sólo cinco años después tuve ocasión de conocer a Clarice Lispector. De paso por Rio de Janeiro, en 1971, y gracias a los cariñosos oficios de la novelista Nélida Piñón, gran amiga de la narradora brasileña, pude visitarla en su luminoso departamento del Leme. El cuarto grande, de paredes blancas, estaba decorado con libros, cuadros, grabados, fotografías y flores. En medio, delgada, hermosa, quieta, contenida, estaba Clarice. Sus ojos se fijaban en uno con una mirada en la que no había tensión ni interrogación ni curiosidad, sino asombro. El asombro ante la infinita multiplicidad del universo, ante el espectáculo inagotable de seres y objetos. Clarice miraba, pero era como si sus ojos fueran la puerta para otro universo, un universo que estaba allí, pero no era del todo accesible.

El habitante de aquellos ojos se asomaba apenas. Era posible entender que el mundo interior a que daban acceso esos ojos era infinito. Pero digo mal: no había acceso. Los ojos eran una superficie misteriosa. Borges ha definido al hecho estético como la inminencia de una revelación que no se produce. La primera impresión que dejó Clarice Lispector en mí fue ésa. Que no hubiera acceso, o que el acceso estuviera en otro lado (en sus textos), no me importó. El hecho estético, los ojos de Clarice, no era menos cierto. La miraba y la veía cumplir con el ritual sobrio y delicado de toda dueña de casa: ofrecer asiento, una bebida, interesarse por detalles triviales. Pero nada de lo que hacía Clarice podía ser trivial, porque sus gestos tenían otro tiempo, sus palabras otro tono, su mirada otra dimensión. No me acuerdo mucho (esto pasó en el invierno brasileño de 1971) de qué hablamos exactamente. Pero sé que hablamos de sus libros y, sobre todo, de una novelita policial para niños que había publicado hacía unos años: O misterio del coelho pensante (1967), en que la desaparición del conejo es pretexto para una aventura misteriosa y sin solución.

Si Kafka hubiese escrito para niños, tal vez su novelita sería parecida a ésta. Aunque nadie puede escribir parecido a Clarice. Ya en la época de mi visita, Clarice había sufrido un horrible accidente (un cigarrillo mal apagado incendió la cama en que dormía), y una de sus hermosas manos y una pierna habían sido alcanzadas por el fuego. La manera delicada, firme, pero no ostentosa, con que Clarice usaba aquella mano derecha, mutilada, era también una revelación en suspenso. Todo lo que ella hacía, las referencias a un amigo común, un libro o un cuadro (en una de las paredes un retrato que le había hecho el pintor italiano De Chirico en Suiza), estaban rodeadas de un aura. La visita me conmovió por la simplicidad de recursos: Clarice actuaba en otra dimensión, pero sus artificios eran tomados de lo cotidiano. La magia ocurría en la tarde, a la luz fuerte del invierno carioca que entraba, tamizada, por la enorme ventana. Los instrumentos de sus hechizos eran una taza de café, un cigarrillo, un libro con una dedicatoria simpática y trivial. No era, no, el decorado gótico de la hechicera medieval ni el salón recargado de la seductora del decadentismo. Pero, a plena luz, y sin ninguna parafernalia, Clarice Lispector creaba (como en sus libros) un ámbito de magia y hechicería. [...]

Otra vez (y ésta sí la recuerdo gráficamente, porque luego supe que sería la última) Nélida y yo nos encontramos con ella en la Galería Bonimo, de Rio, en una exposición de las extraordinarias telas de María Bonomi. En medio de la algarabía de un vernissage carioca, conseguí conversar un poco con Clarice. Hay una extraña foto de ese momento en que ella y yo estamos enfrentados y de perfil, absortos en una conversación, en medio del mar de cabezas que se disparan en todas direcciones y estallan contra las grandes telas del fondo. Era un día de ese invierno, tibio y algo viscoso, que caracteriza tanto a Rio en julio o agosto, y estaba lloviendo intermitentemente. Tal vez cansada del ruido, Clarice me pidió que la acompañase a buscar un taxi para volver a casa. Fuimos hasta la avenida Nossa Senhora de Copacabana, una de las más infernales de la infernal Copacabana, y mientras discutíamos sobre la mejor estrategia para conseguir un taxi los días de lluvia y el peligro de los asaltos en las calles mal iluminadas de Rio, mi total imprevisión del futuro me hizo conseguir uno casi de inmediato, poner a Clarice en él y despacharla muy contento y con prisa a su destino.

No sabía (siempre nos creemos inmortales y generosamente extendemos esta condición a nuestros amigos) que no la vería más. Tampoco sabía que estaba ya enferma de cáncer y que, unos meses después, el 9 de diciembre de 1977, moriría en el Hospital de la Lagos Rodrigo de Freitas. Todo esto lo supe mucho más tarde por Nélida, y ya no podía hacer nada. Pero aquella noche de mediados de 1975, en Rio, me volví a la Galería muy orondo porque, en un plazo mínimo, había conseguido un taxi para Clarice Lispector. 
III

El inevitable tópico de conversación en aquel último encuentro había sido su asistencia a un Congreso Mundial de Brujería que tuvo lugar en Colombia aquel mismo año. La prensa brasileña se había encargado de destacar la extraña invitación, y a su regreso a Rio los periodistas no se cansaban de asombrarse 1) de que Clarice hubiese sido descubierta por los latinoamericanos (como ellos llaman a los hispanoamericanos, como si Brasil no estuviese en América Latina, y 2) de que la novelista brasileña hubiese tenido suficiente sentido del humor para asistir [...]. (Rodríguez Monegal, 1984: 231-234)

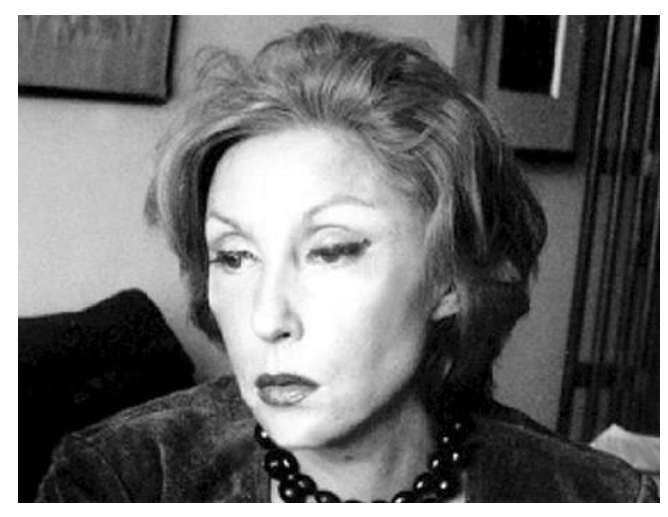

$*$

En efecto, de entre el corpus enfermo de estas escritoras - de una productividad tan heterogénea como maníaca en sus inquietudes- y en la postura-ethos encarnados que hacen sensible el carácter singular de su malestar, como estremecimiento de la forma, una posibilidad de salud parece materializarse. Me refiero a lo que -muy distantes y casi radicalmente distintas- las aproxima y las distancia: sus enrevesadas maneras, intersticiales, de (re)presentar lo vivo que pulsa en las entrañas de lo humano; y sus maneras de quedarse impresas en el gesto de esa (re)presentación. Algo en ellas consigue hacerse sensible allí. En el fragmento intenso de escritura que se vierte en el acto desquiciado de la escritora. En los restos de cuerpo que marginalmente acompañan una productividad plástica proliferante y proliferada en la manía que los comunica. En el exceso trágico de la semiosis desencadenada por un acaso en la cotidianidad, puesto en la boca contenida de quien mira y escucha en la escritura cada vez. Es decir: en «eso» alrededor de lo cual ellas se pliegan, despliegan y repliegan sin cesar -el obsceno paso al acto de la fantasía, la hambrienta voracidad de lo orgánico, la potente literalidad del fantasma-, «algo» que es del orden de lo pulsional consigue ser escuchado cuando menos como síntoma, por la máquina cultural que se apresura entonces a otorgarles un lugar privilegiado entre las «extrañezas» que habitan «exceptuadas» en la linealidad de su Historia.

\section{Referencias bibliográficas}

Agamben, G. (2005): Profanaciones. Barcelona, Anagrama.

Antelo, R. (2014): «Jorge Larco e o Conceito de Cena». Presentado en un coloquio de la Associação de Criticos de Arte do Brasil, Florianópolis [Material mimeografiado].

BARTHES, R. (1973): El placer del texto. México, Siglo XXI, 1991.

Bataille, G. (1967): «La noción de gasto», en F. Muñoz de Escalona, comp. y trad., La parte maldita. Barcelona, Icaria, 1987.

Bombal, M. L. (1938): La amortajada. Santiago de Chile, Nascimento, 1941. 
CRÓQUer, E. (1999): El Gesto de Antígona o La escritura como responsabilidad (Clarice Lispector, Diamela Eltit, Carmen Boullosa). Santiago de Chile, Cuarto Propio.

Deleuze, G. (1993): Crítica y clínica. Barcelona: Anagrama, 1996.

Didi-Huberman, G. (1982): La invención de la histeria. Charcot y la iconografía fotográfica de la Salpêtrière. Trad. de Tania Arias y Rafael Jackson. Madrid, Cátedra, 2007.

FloreS, J. S. (2015): «El saber en la tierra del Rey Mocho». Texto realizado para la cátedra de Clínica Psicoanalítica II. Caracas, Centro de Investigación y Docencia en Psicoanálisis (CID). Foucault, M. (1971): El orden del discurso. Buenos Aires, Tusquets, 1990.

FreUd, S. (1895): «Estudios sobre la histeria», en Obras completas. Trad. de Luis López-Ballesteros y De Torres. Madrid, Biblioteca Nueva, 1996.

IsRAËL, L. (1979): El goce de la histérica. Trad. de Ana Goldar y Marta Giacomino. Buenos Aires, Editorial Argonauta.

Khalo, F. (1944-1945): El Diario de Frida Kahlo. Un íntimo autorretrato. Intr. de Carlos Fuentes. Ensayo y Comentarios de Sarah M. Lowe. Madrid, Debate, 1995 [edición facsímil].

KristeVA, J. (1969): Semiótica I. Madrid, Fundamentos, 1981.

LACAN, J. (1971): «Lituraterre». [Publicado originalmente en la revista Littératura 3, número dedicado a Literatura y psicoanálisis], en http://www.lacanterafreudiana.com.ar/2.1.7.7a\%20 anexo\%20LITURATERRE\%20\%20S18.pdf

(1992): El reverso del psicoanálisis. Seminario 17. Buenos Aires, Paidós.

LisPector, C. (1964): A Paixão segundo G.H., B. Nunes, coord. Brasilia, Coleção ArquivosUnesco, 1988.

Maingueneau, D. (2009): «Autor e imagen de autor en el análisis del discurso», en J. Zapata, coord., La invención del autor. Nuevas aproximaciones al estudio sociológico y discursivo de la figura autorial. Medellín, Editorial Universidad de Antioquia, 2014.

Meizoz, J. (2009): «Aquello que le hacemos decir al silencio: postura, ethos, imagen de autor», en J. Zapata, coord. La invención del autor. Nuevas aproximaciones al estudio sociológico y discursivo de la figura autorial. Medellín, Editorial Universidad de Antioquia, 2014.

NANCY, J.-L. (2001): «¿Cómo se escucha la música?», en C. Rodríguez Marciel, ed., La partición de las artes. València, Pre-Textos-Universidad Politécnica, 2013.

PADRÓN, C. (2014): «Psychoanalysis and the Fragmentary: The Uncanny, Enactments, and the Unconscious as an After-Effect Producing Surface». Texto presentado en el Ciclo de conferencias «Potluck Papers» en IPTAR (Institute for Psychoanalytic Training and Research), Nueva York [Material mimeografiado].

RAmos, J. (2010): «Descarga acústica», Papel Máquina, 4, pp. 49-77.

Rodríguez Monegal, E. (1984): «Clarice Lispector en sus libros y en mi recuerdo», Revista Iberoamericana, L/126 (enero-marzo), pp. 231-238.

TORRAS FRANCÉS, M. (2015): «Y el verbo se hizo carne. Vías de encarnación de un corpus-cuerpo autorial». Estudios. Revista de Investigaciones Literarias y Culturales, [en prensa]. 